\title{
Polyurethane composite adsorbent using solid phase extraction method for preconcentration of metal ion from aqueous solution
}

\author{
O. F. Olorundare $\cdot$ T. A. M. Msagati • \\ R. W. M. Krause $\cdot$ J. O. Okonkwo • \\ B. B. Mamba
}

Received: 11 November 2013/Revised: 26 May 2014/ Accepted: 8 July 2014 / Published online: 29 July 2014

(C) Islamic Azad University (IAU) 2014

\begin{abstract}
Polyurethane composite adsorbent polymeric material was prepared and investigated for selected solidphase extraction for metal ions, prior to its determination by inductively coupled plasma optical emission spectrometry. The surface characterisation was done using Fourier transform infrared spectroscopy. The separation and preconcentration conditions of the analytes investigated includes influence of $\mathrm{pH}$, sample loading flow rate, elution flow rate, type and concentration of eluents. The optimum $\mathrm{pH}$ for the highest efficient recoveries for all metal ions, which ranged from 70 to $85 \%$, is $\mathrm{pH} 7$. The metal ions were quantitatively eluted with $5 \mathrm{~mL}$ of $2 \mathrm{~mol} / \mathrm{L} \mathrm{HNO}_{3}$. Common coexisting ions did not interfere with the separation. The percentage recovery of the metal ions ranged between 70 and $89 \%$, while the results for the limit of detection and limit of quantification ranged from 0.249 to 0.256 and 0.831 to 0.855 , respectively. The experimental tests showed good preconcentration results of trace levels of metal ions using synthesised polyurethane polymer adsorbent composite.
\end{abstract}

O. F. Olorundare - T. A. M. Msagati $(\bowtie)$ - B. B. Mamba Department of Applied Chemistry, University of Johannesburg, P.O. Box 17011, Johannesburg, South Africa

e-mail: tmsagati@uj.ac.za

R. W. M. Krause

Department of Chemistry, Rhodes University, P.O. Box 94, Grahamstown 6140, South Africa

J. O. Okonkwo

Department of Environmental, Water and Earth Sciences, Faculty of Science, Tshwane University of Technology, Private Bag X680, Pretoria 0001, South Africa
Keywords Heavy metals - Polymer adsorbent composite (PCAD) · Preconcentration · Solid phase extraction (SPE) · Inductively coupled plasma optical emission spectroscopy (ICP-OES)

\section{Introduction}

Analyses of both inorganic and organic compounds in environmental samples, especially waste and natural water samples, have been performed on a continuous basis in order to monitor and assess the level of environmental pollution associated with health issues which have been on the increase in recent times (Jain et al. 2003; Kocaoba and Akyuz 2005; Bulut and Tez 2007; Rezaei et al. 2009; Mittal et al. 2009; 2010; Rafati et al. 2010; Gupta et al. 2011a, b, c). Moreover, direct analysis of these inorganic compounds especially metal ions by atomic spectroscopy method, such as inductively coupled plasma atomic emission spectroscopy (ICP-AES), inductively coupled plasma optical emission spectroscopy (ICP-OES), and flame atomic absorption spectroscopy (FAAS), is often difficult due to the matrix interference and low concentration, and this make it difficult for the instrument to detect the ion which might be out of range of instrument's detection limit. Thus, a preconcentration method for the enrichment of these metal ions is necessary (Gupta et al. 2004; Kocaoba and Akyuz 2005; Alkan et al. 2008; Madrakian et al. 2008; Gupta et al. 2010).

Numerous preconcentration and separation techniques application have been reported for metal-ion analysis, which include cloud-point extraction (CPE) (Anthemidis et al. 2001, 2002), co-precipitation (Duran et al. 2009), electrochemical deposition (ECD) (Soylak and Tuzen 
2008), flotation (Pan et al. 2007), liquid-liquid extraction (LLE) (Candir et al. 2008), solid-phase extraction (SPE) (Otero-Romani et al. 2005; Elci et al. 2008; Huang et al. 2008; Chen et al. 2009), solid-phase microextraction (SPME) (Camel 2003; Chen et al. 2009), etc. However, SPE is the preferred method mainly due to its simplicity, direct application in microlitre $(\mu \mathrm{L})$ volume, speed, minimal sample loss, higher preconcentration factor, rapid phase separation, cost and time saving (Bulut and Tez 2007; Chen et al. 2009; Mohammadi et al. 2011).

The SPE method is based on the principle of analyte transfer from the aqueous medium, i.e. phase, to the active sites on the solid phase of an adsorbent (Bulut and Tez 2007). Numerous technologies involving adsorbents have been applied as preconcentration adsorbents for metal ions, including alumina ( $\mathrm{Li}$ et al. 2002; Absalan and Mehrdjardi 2003), activated carbon (AC) (Ensafi et al. 2003; Gupta et al. 2012a, b; Olorundare et al. 2012), C18 cartridge silica, chelex-100 (Ferri and Sangiorgio 1996), polyurethane foam (Anthemidis et al. 2002; Pinto et al. 2004), microcrystalline naphthalene (Candir et al. 2008; Elci et al. 2008), nanoparticles (Gupta and Nayak 2012; Sanghavi et al. 2013), silica gel (Akl et al. 2004), cyclodextrins CDs (Krause et al. 2010), zeolites (Ngah et al. 2012), and clay (Kiliaris and Papaspyrides 2010). However, the development of purification and extraction methods using these adsorbents for the enrichment of metal ions in environmental samples has been a challenge due to drawbacks which have limited their application for effective monitoring and curtailments of pollutants in the environment (Pinto et al. 2004; Alkan et al. 2008; Castro et al. 2011). Recently, there has been a growing interest in environmentally safe application of these adsorbent materials (Pinto et al. 2004, 2005). This is because most of these adsorbents, available in the market for environmental application, are either obtained in pellets or powder form (Pinto et al. 2004; Oprea 2011). The present form of these adsorbents' physical appearance hinders their optimum application in the water-treatment process. Furthermore, these factors have restricted the industrial application of these adsorbent materials, especially those applied in separation technology (Pinto et al. 2004, 2005). Apart from their physical properties, the regeneration of the spent adsorbent materials to their original state of adsorption capacity is a challenge because of its cost implication and heat-controlled environment required for their treatment (Gayatri and Ahmaruzzaman 2010). This operational drawback has raised questions of development of composite support materials that could be easily regenerated without the thermal energy input (Gayatri and Ahmaruzzaman 2010). An approach of mitigating a solution to these drawbacks is production of an adsorbent material as a support in the form of a composite material applicable for water treatment (Pinto et al. 2004). The material for composite production as in the case of a polymer must be a blend of polymeric material that will be able to improve or modify the physicochemical properties of the new polymeric composite material (Oprea 2008).

This method is a way of obtaining materials with the required engineering characteristics such as better chemical properties, biocompatibility, biological activities, thermal stability, open cell content, specific gravity and hydrophobicity properties. An improved way of enhancing the application of polymeric adsorbent material is to support the adsorbent materials in a template of porous matrices. This template can be used to support adsorbent material with desired characteristics for purification purposes, thus allowing for easier formulation cum production of blend filler with both physical and chemical characteristics closer to the desired adsorbent composite (Pinto et al. 2004, 2005; Oprea 2008).

In this study, polymeric composite adsorbent material (PCAD) was synthesised and characterised in our water research laboratory at the University of Johannesburg between April and October of 2013. The prepared composite material showed great affinity, high enrichment and less binding time with metal ions. The SPE extraction method was studied for $\mathrm{Cd}(\mathrm{II}), \mathrm{Cr}(\mathrm{III})$, and $\mathrm{Pb}$ (II) metal ions. The parameters that influence the sorption, extraction and elution efficiency of the metal ions were also studied.

\section{Materials and methods}

Reagents and standards

All reagents were analytical grade unless otherwise stated and Millipore water (Merck, Darmstadt, Germany) of $18 \mathrm{M} \Omega$ was used throughout the experiments. Concentrated nitric acid $\left(\mathrm{HNO}_{3}\right)(70 \%)$ and hydrochloric acid $(37 \% \mathrm{HCl}$ w/v) were purchased from Sigma-Aldrich (St. Louis, MO, USA). All plastics and glassware were cleansed by soaking in dilute $\mathrm{HNO}_{3}$ and were rinsed with distilled water prior to use. The metal-ion stock solution (1,000 mg/L) (Merck, Darmstadt, Germany) was prepared daily for obtaining reference and working solutions. The working standard solutions were prepared by mixing appropriate dilution of the stock standard solutions with distilled water. Ammonium acetate buffer solution (1 M) was prepared by mixing appropriate amounts of ammonia $25 \%$ solution (Sigma-Aldrich St. Louis, MO, USA) and glacial acetic acid $97 \%$ solution 
(Sigma-Aldrich St. Louis, MO, USA), which was then followed by dilution with water to a final $\mathrm{pH}$ of 9.0 using Mettler Toledo pH meter model 20, Greifensee, Switzerland.

The working solutions were freshly prepared on a daily basis by the appropriate dilution of the stock with deionised water, while the calibration standards were prepared with serial dilutions of the stock mixture at 10, 20, 40, 60, 100, 200 and $500 \mathrm{ng} / \mathrm{L}$. Hydrochloric acid $\mathrm{HCl} 0.1 \mathrm{M}$ and sodium hydroxide $\mathrm{NaOH} 0.1 \mathrm{M}$ solution were used to adjust the $\mathrm{pH}$ values of the working solutions. 1,2-dimethoxy-3-(1-methoxypropan2-yloxy)propane (Sigma-Aldrich St Louis, MO, USA) was used as a triol, dibutyltin dilaurate (DBTL $>97 \%$, Merck, Darmstadt, Germany) was used as a catalyst, silicone oil and castor oil (Sigma-Aldrich St Louis, MO, USA) were used as a foam stabiliser. The isocyanates used were 4,4'-methylene diphenyl diisocyanate (MDI $>98 \%$ Sigma-Aldrich St Louis, MO, USA) and 1,6-hexamethylene diisocyanate (HMDI $>98 \%$ Lupanat, M 50, BASF Lemförde, Germany).

A Strata ${ }^{\mathrm{TM}}$ C18-E SPE C 18 (EC) cartridge $(0.5 \mathrm{~g}, 6 \mathrm{~mL}$, and polypropylene column) purchased from Phenomenex companies, Torrance CA, USA, was used for preconcentration. The porous frit was placed at the bottom and at the top of the column for allowing the adsorbent to settle. The SPE was carried out in a VasMaster-20 sample SPE station (Supelco, PA, USA). The SPE station was used for both sample loading and elution desorption flow rate.

\section{Instruments}

The analytes (metal ions) were determined using Spectro ARCOS inductively coupled plasma optical emission spectrometry ICP-OES with radial plasma equipped with Cetac ASX-520 auto-sampler (Borscht, Kleve, Germany). The operating conditions used for ICP-OES spectrometry during the measurements were as follows: $\mathrm{RF}$ generator forward power; $1,400 \mathrm{~W}$, plasma argon flow rate $13 \mathrm{~L} / \mathrm{min}$, auxiliary argon flow rate $2.00 \mathrm{~L} / \mathrm{min}$, and nebuliser argon flow rate $0.95 \mathrm{~L} / \mathrm{min}$. The most prominent atomic and ionic analytical lines of metal ions selected for this experimental study were Cd $226.5 \mathrm{~nm}$, $\mathrm{Cr} 205.55 \mathrm{~nm}$, and $\mathrm{Pb} 220.35 \mathrm{~nm}$. A cross-flow nebuliser and double-pass spray chamber were used throughout the measurement process. The calibration standards for ICPOES analysis were prepared from high-purity compounds by diluting commercially available $1,000 \mathrm{mg} / \mathrm{L}$ solutions (Merck, Darmstadt, Germany) of varying elements in $1 \% \mathrm{HNO}_{3}$.
Table 1 Composites of formulation of polyurethane composite adsorbent

\begin{tabular}{lll}
\hline & \multicolumn{2}{l}{ Formulation series $^{\mathrm{a}}$} \\
\cline { 2 - 3 } & HMDI (A) & MDI (B) \\
\hline Polyol (g) & 30 & 30 \\
DBTL (g) & 0.23 & 0.23 \\
Silicone oil: castor oil (1:1) (v/v) & 0.8 & 0.8 \\
Water content (\%) & $3-5$ & $1-5$ \\
Diisocyanate (g) & 14.2 & 14.2 \\
Fillers (g) & 0.2 & 0.2 \\
\hline
\end{tabular}

$\overline{\text { a }}$ NCO index $=105 \%, \mathrm{NCO}=$ polyurethane bond (Pan et al. 2007; Pinto et al. 2004)

Polyurethane synthesis

The method of preparation was done according to Pinto et al. (2004) with slight modifications. A bulk total $50 \mathrm{~g}$ of the material, i.e. quantities required for the formation of a polyurethane composite such as polyol, distilled water, castor oil/silicone oil (1:1) and catalyst were added into a polyethylene flask and mixed vigorously for $1 \mathrm{~min}$ with a mechanical stirrer to obtain a formulated polyol prepolymer. The isocyanate was then added to the same flask followed by addition of the various fillers and stirred vigorously for about $20 \mathrm{~min}$. The resulting mixture, a composite material was left undisturbed for about $60 \mathrm{~s}$ to allow the formulation to grow and form a PU polymer composite. The PU polymer composite was then immediately added into a mould and kept inside the oven at $60{ }^{\circ} \mathrm{C}$ for $60 \mathrm{~min}$. The resulting formulation was thereafter ground to a powder and kept in desiccators until further analysis. Several formulations were tested for clarity but only one is reported here (Table 1). In order to maintain the urethane $\mathrm{NCO}$ index, isocyanate and water composition were varied (Table 1) for the series formulation.

\section{Solid-phase extraction (SPE) cartridge}

The SPE commercial cartridge was replaced with polyurethane composites adsorbent (PCAD) (polymeric material containing polyurethane, $\mathrm{AC}$ and $\beta-\mathrm{CD}$ as filler) packed cartridge, which was prepared by modifying a Strata ${ }^{\mathrm{TM}}$ C18-E SPE $\mathrm{C}_{18}$ (EC) cartridge $(0.5 \mathrm{~g}, 6 \mathrm{~mL}$ polypropylene). The $\mathrm{C}_{18}$ packing of the cartridge was evacuated, and then $0.5 \mathrm{~g}$ of PCAD was packed into the cartridge. The $20 \mu \mathrm{m}$ polypropylene lower and upper frits remained at each end of the cartridge to serve as support holders for PCAD packing. The outlet tip of the 
cartridge was connected to a vacuum pump (Shimadzu, Japan) and the inlet end of the cartridge was connected to PTFE suction tube whose other end was inserted into sample solution. The entire SPE set-up assembly was carefully washed with methanol before use in order to reduce the interferences of the organic and inorganic contaminants.

\section{Procedure}

Before the preconcentration enrichment step, the PCAD packed cartridge was firstly preconditioned by washing using triple distilled water followed by conditioning with $10 \mathrm{~mL}$ of ammonium acetate buffer $(1.0 \mathrm{M}, \mathrm{pH}$ 9.0). The sample solutions were then loaded onto the preconditioned PCAD cartridge at a constant flow rate. After the loading stage, the PCAD packed cartridge was then washed with $5 \mathrm{~mL}$ ammonium acetate buffer. The washing stage before metal-ion desorption was engaged in order to eliminate concomitant elements that could be partially adsorbed by the PCAD polymeric material. The retained metal ions were then eluted with nitric acid at a constant flow rate into ICP vials. The metal concentrations in the final solutions were then determined by ICPOES. The same protocol was employed for the blank solutions. After each run, the PCAD polymeric material in the cartridge was washed with $20 \mathrm{~mL}$ of distilled water and then stored for further experiments. The $\mathrm{pH}$ of samples was adjusted accordingly with $1 \mathrm{~mL}$ of $0.1 \mathrm{M} \mathrm{HCl}$ or $0.1 \mathrm{M} \mathrm{NaOH}$ solution. Thereafter a known volume of sample solutions were aspirated through the modified SPE C18 column at a controlled flow rate and the eluate obtained was discarded. However, when the whole sample had passed through the SPE column, $10 \mathrm{~mL}$ of purified water was used to remove the impurities or the co-adsorbed matrix materials from the cartridge. The influence of sample solution $\mathrm{pH}$, sample volume, sample loading flow rate, elution flow rate, type and concentration of eluents were investigated.

\section{Results and discussion}

Characterisation of the polyurethane composite adsorbents

The structure and surface functional groups on the PCAD with different fillers was investigated and compared by using Fourier transform infrared (FT-IR) and scanning electron microscopy (SEM) for their characterisation.

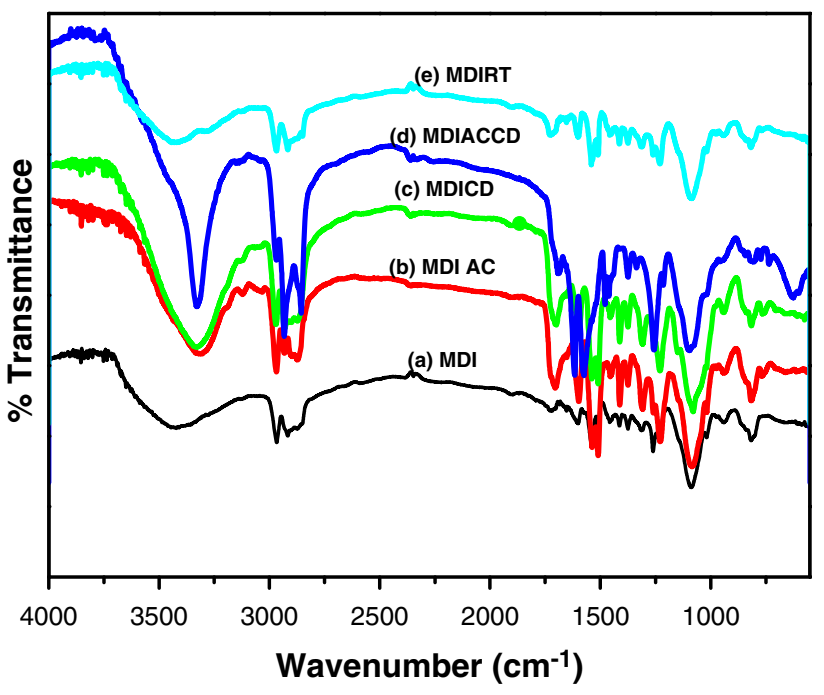

Fig. 1 FT-IR transmission spectra of PCAD spectra of (a) MDI; (b) MDIAC; (c) MDICD; (d) MDIACCD; and (e) MDIRT

\section{FT-IR spectroscopy}

The surface functional groups on the PCAD material were investigated using FT-IR spectroscopy (Nicolet IS10 SMART ITR, Madison, WI, USA) equipped with Golden Gate single reflection attenuated total reflection (ATR) accessory. All the polymeric materials, i.e. methylene diisocyanate (MDI), methylene diisocyanate-activated carbon (MDIAC), methylene diisocyanate-beta $(\beta)$ cyclodextrin ( $\beta$-CD) (MDICD), methylene diisocyanate-activated carbon-beta $(\beta)$ cyclodextrin (MDIACCD), and methylene diisocyanate raw tassel (MDIRT) were prepared onto FT-IR grade $\mathrm{KBr}$ crystals at a sample-to-crystal ratio of 20:80. Figure 1 shows the FT-IR spectra of the polymeric materials.

The typical FT-IR spectra of the polymeric material PCAD for the composite adsorbent are shown in Fig. 1. All the characteristic absorption peaks of PCAD polymeric materials, around $3,430-3,300 \mathrm{~cm}^{-1}$ (free $\mathrm{O}-\mathrm{H}$ stretching vibration, $\mathrm{N}-\mathrm{H}$ stretching of hydrogen bonded amino group), $2,970-2,840 \mathrm{~cm}^{-1}\left(\mathrm{CH}_{2}\right.$ and $\mathrm{CH}_{3}$ stretching vibration $), 1,720-1,600 \mathrm{~cm}^{-1} \quad(\mathrm{C}=\mathrm{O}$ stretching of bonded carbonyl), $1,400-1,305 \mathrm{~cm}^{-1} \quad(\mathrm{C}-\mathrm{N})$ and $1,100-1,000 \mathrm{~cm}^{-1}(-\mathrm{C}-\mathrm{O}-\mathrm{C})$ revealed the existence of the urethane in the synthesised cross-linked PCAD and fillers in the polymeric materials. The absorption of NCO from the PCAD polymeric materials takes place between 2,300 and 2,200 $\mathrm{cm}^{-1}$ in different spectra for MDI-based PCAD polymeric materials which was not observed in any of the resulting polymeric materials, thus indicating the absence of free NCO groups. All the peaks at $3,430-3,300 \mathrm{~cm}^{-1}$ were very broad for the PCAD except 

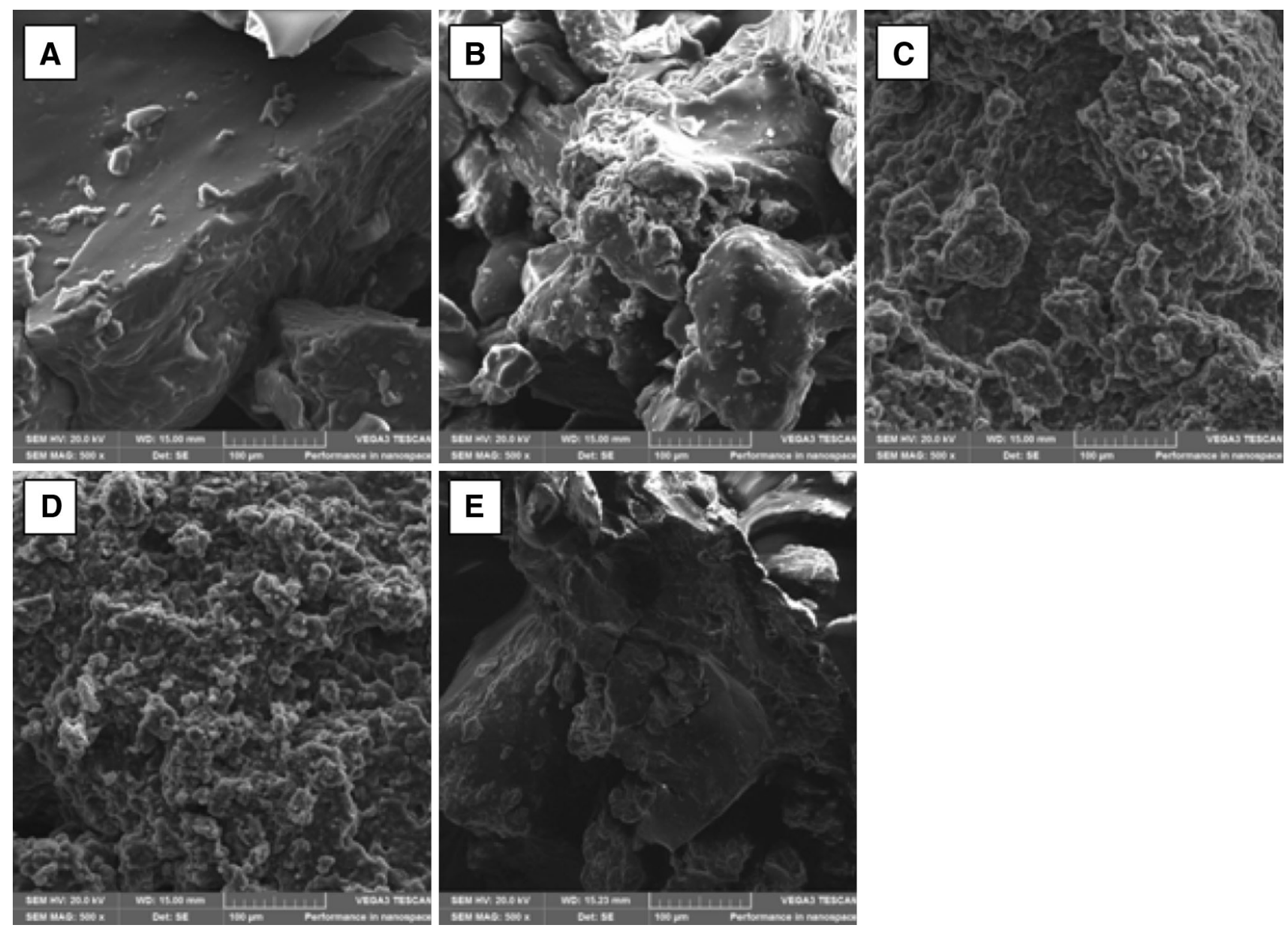

Fig. 2 Scanning electron microscope (SEM) images of PCAD polymeric material at $\times 500 \mathrm{~nm}$ : a MDI; b MDIAC; c MDICD; d MDIACCD; e MDIRT

for MDIACCD that has a sharp peak at this region. These peaks were shifted to higher absorption band than $3,300 \mathrm{~cm}^{-1}$ when compared to the broad absorption of $\mathrm{OH}$ stretching vibration in the range of $3,500-3,300 \mathrm{~cm}^{-1}$. This might be due to the $\mathrm{OH}$ stretching vibration from $\beta$-CD (Pinto et al. 2004; Oprea 2011).

However, with the introduction of more filler into the PU matrix, in the PCAD polymeric material, the peak at $1,095 \mathrm{~cm}^{-1}$ for MDIACCD shifts to $1,018 \mathrm{~cm}^{-1}$ for MDI (Fig. 1). Similar observations were noticed at peak $784 \mathrm{~cm}^{-1}$ for MDIAC which shifted to $773 \mathrm{~cm}^{-1}$ for MDIACCD and was completely absent in both MDI and MDIRT. This peak shift is attributed to out-of-plane vibration of the $\mathrm{CO}-\mathrm{NH}$ group. The stretching vibration observed for MDI and MDICD at $940 \mathrm{~cm}^{-1}$ is due to the $\mathrm{C}-\mathrm{O}$ bond stretching vibration. The $\mathrm{C}-\mathrm{O}$ bond stretching vibrations observed at $818-816 \mathrm{~cm}^{-1}$ in MDI, MDICD, and MDIRT were due to anhydroglucose ring stretching vibration (Pinto et al. 2004; Oprea 2011). The hydroxyl $(-\mathrm{OH})$ groups and the $-\mathrm{O}-$ groups from the filler, especially $\beta-C D$ and $A C$, form $\mathrm{H}$ bonds with $\mathrm{C}=\mathrm{O}$ groups and $\mathrm{N}-\mathrm{H}$ groups from the polymeric PCAD material. This formation, i.e. hydrogen bond formation between the PU macromolecules and the fillers, results in the increase of physical cross-links in the PCAD polymeric composite materials (Pinto et al. 2004; Oprea 2011).

\section{Surface morphology of PCAD using SEM}

The surface morphology of PCAD polymeric material was observed by scanning electron microscope (SEM) (TESCAN VEGA 3 LM, Czech). The representative SEM images (Fig. 2) reveal the microstructure transformation on the surface of the polymeric material. All the PCAD polymeric material shows different surface morphology. 
Fig. 3 SEM and EDX images of PCAD polymeric material at $\times 500 \mathrm{~nm}$ : a MDI; b MDIAC; c MDICD; d MDIACCD; e MDIRT
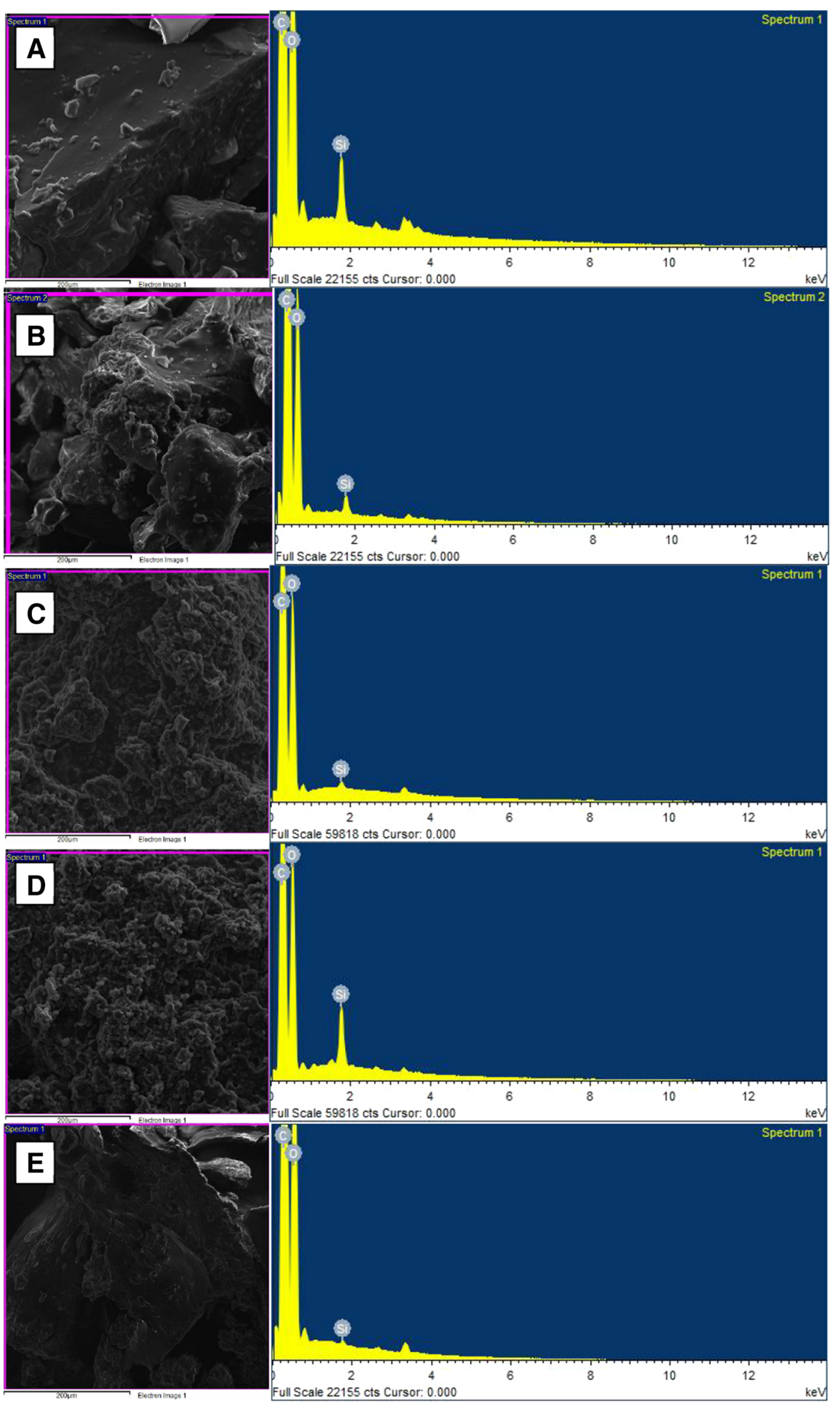


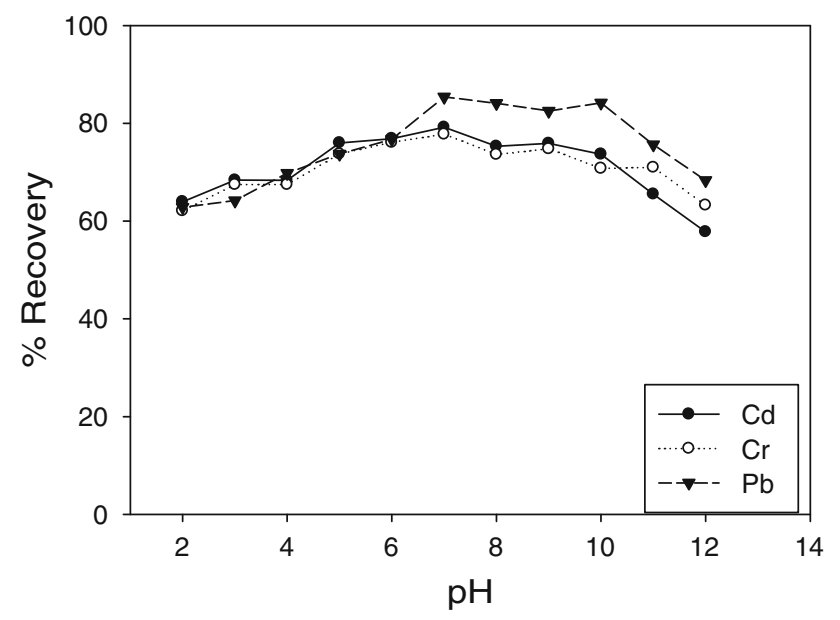

Fig. 4 Influence of solution $\mathrm{pH}$ values on the recoveries of metal ions in aqueous medium

The results show that the filler contributes significantly to the final texture of the polyurethane composite material PCAD. The addition of the filler, indicated in Fig. 2a (MDI) to Fig. 2e (MDIRT), shows that the soft segment part of the urethane chain NCO plays a predominant role, compared to the hard segment, especially in Fig. 2b-d. As can be seen in Fig. $2 d$ the MDIACCD containing $\beta-C D$ and $\mathrm{AC}$ is shown to be more porous than the remaining PCAD polymeric material. This might be due to the effect of $\beta$ $\mathrm{CD}$ which has inclusion properties and can incorporate $\mathrm{AC}$ as a guest into its moiety. The result for Fig. 2e (MDIRT) shows that the raw tassel RT is acting as a binder to reinforce the hard segment part of the PU chain, hence the flatter and smoother surface. The MDI surface (Fig. 2a) is smoother than the other because of the absence of the filler in the polymeric material.

\section{Surface morphology of PCAD using SEM coupled with energy dispersive $X$-ray $(E D X)$}

The provided sample was anchored onto the sample holder and inserted into TESCAN VEGA 3 LM SEM integrated fully with a selected EDX microanalysis which was an oxford system. The working voltage of $20 \mathrm{kV}$ was used to analyse the composite material. Approximately $70 \%$ of the study area was scanned for particles, avoiding the edges for unwanted particles due to handling. Figure $3 a-e$ shows the residue observed on the composite material. Particles containing high signal of carbon $(\mathrm{C})$, oxygen $(\mathrm{O})$, and silicon $(\mathrm{Si})$ was from the starting material which contain silicone oil and polyurethane linker diisocyanate. Particles containing traces of sodium $(\mathrm{Na})$, together with potassium $(\mathrm{K})$, chlorine $(\mathrm{Cl})$, cobalt $(\mathrm{Co})$, and Calcium $(\mathrm{Ca})$ were probably from organic dust in sample chamber (result were not reflected on the EDX graph). The high percentage of C in all the samples was due to the starting material (Table 1) and carbon tape used to collect the particles therefore, $\mathrm{C}$ signal in each of the spectra was partially associated with the tape. While $\mathrm{O}$ and $\mathrm{Si}$ were from also from the starting material.

Influence of solution $\mathrm{pH}$

The $\mathrm{pH}$ of aqueous solution sample plays major role for quantitative retention of analytes because of the competitive reactions nature, between metal ions and hydrogen ions in aqueous solution (Zhang et al. 2010). Furthermore, $\mathrm{pH}$ influences both the chemistry of metal ions and functional groups on polymeric material due to its metal-retention ability from aqueous solution which is a pH-dependent process (Baraka et al. 2007).

The influence of $\mathrm{pH}$ on the retention of analytes [Cd(II), $\mathrm{Cr}(\mathrm{III})$ and $\mathrm{Pb}(\mathrm{II})$ ions] onto the polymeric material was investigated in the $\mathrm{pH}$ range of 4.0-10.0. The sample solutions of each metal ion were investigated by varying the $\mathrm{pH}$ of metal solutions subjected to extraction experiments by using dilute sodium hydroxide or dilute nitric acid solution. The experiment was carried out using $100 \mathrm{~mL}$ of $4 \mathrm{ng} / \mathrm{L}$ for $\mathrm{Cd}, 20 \mathrm{ng} / \mathrm{L}$ for $\mathrm{Cr}$ and $80 \mathrm{ng} / \mathrm{L}$ for $\mathrm{Pb}$ which were passed through the PCAD packed cartridge.

The retained metal ions on the PCAD polymeric material were stripped from the column using nitric acid. The percentage recovery as a function of $\mathrm{pH}$ for all the metal ions is shown in Fig. 4. The plots (Fig. 4) reveal that the PCAD polymeric material can be applied easily in extraction experiments in acidic-neutral medium, because it showed more than $70 \%$ average recovery for all the metal ions in the $\mathrm{pH}$ range of 5.0-8.0 and having the maximum recovery at $\mathrm{pH}$ 7. At a $\mathrm{pH}$ value of above 5, the main group responsible for metal extraction, carboxylic acids (El-Sayed et al. 2010: Castro et al. 2011), is protonated due to the high concentration of $\mathrm{H}^{+}$species. The result also reveals that as the $\mathrm{pH}$ of sample solution increases the concentration of the metal ions also decreases. The recoveries were slightly lower at lower $\mathrm{pH}$ values. This could be due to the competition between the metal ion and hydrogen ion/hydronium ions species for active sites which is responsible for metalion retention (El-Sayed et al. 2010). Thus, the increase in recoveries with increasing $\mathrm{pH}$ (Fig. 4) could be due to a decrease in positive charge density on the PCAD polymeric material. Thus, the reduction of positive charge density will result in the enhancement of metal-ion retention (Gode and Moral 2008). 
The influence of eluent flow rate

The influence of the eluent flow rate is one of the vital parameters affecting preconcentration and recovery percentage of the metal ions. It was observed from the results obtained as shown in Fig. 5, that the recoveries of the metal ions changed between 64 and $82 \%$ for sample flow rates of between 1 and $2 \mathrm{~mL} / \mathrm{min}$ and between 65 and $87 \%$ for sample flow rates of between 3 and $5 \mathrm{~mL} /$ min. Thus, the recoveries of metal ions for the various elution (desorption) flow rates were found to be between 64 and $86 \%$. The variation of the elution flow rate was minimal with not much significant effect. The flow rate of

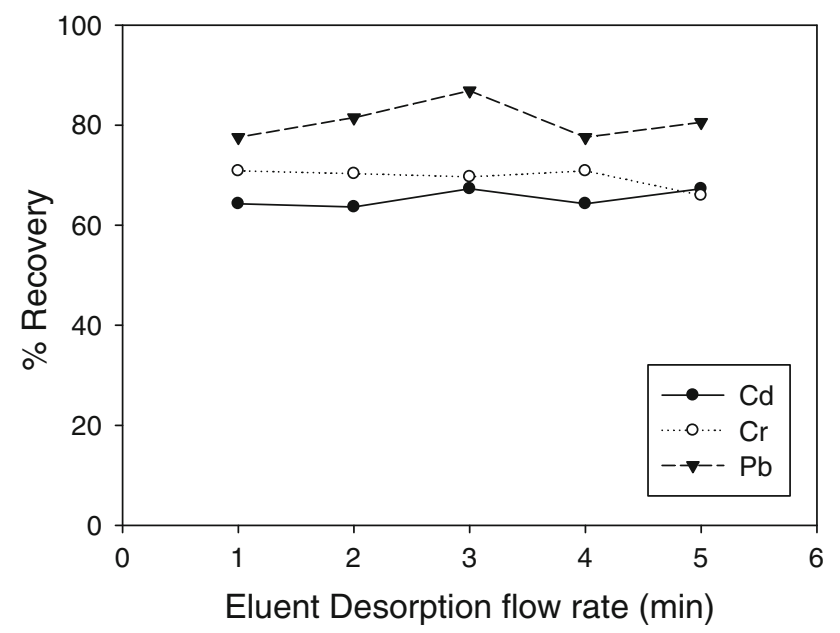

Fig. 5 Influence of desorption flow rate on the recoveries of metal ions in aqueous medium

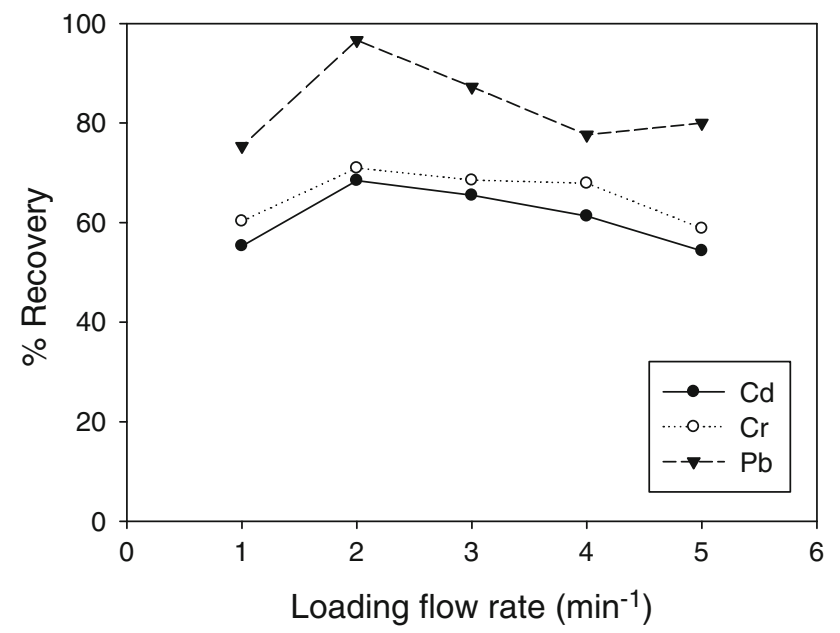

Fig. 6 Influence of sample loading flow rate on the recoveries of metal-ion mixtures in aqueous medium
$3 \mathrm{~mL} / \mathrm{min}$ was selected as the optimum flow rate for the desorption elution and was subsequently used for other experimental test runs.

Influence of sample loading flow rate

The sample loading flow rate is one of the most important parameters in obtaining both the quantitative retention and elution of the analytes, respectively (Sharma and Pant 2009; Sabermahani et al. 2011). The influence of sample loading flow rates on retention of metal ions was investigated in the flow rates ranging between 1 and $5 \mathrm{~mL} / \mathrm{min}$. The result (Fig. 6) shows that at a flow rate of between 1 and $2 \mathrm{~mL} / \mathrm{min}$, there was a sharp increase in the recovery of metal ions. At the flow rates greater than $3 \mathrm{~mL} / \mathrm{min}$, there was a decrease in metal-ion recovery. This could be due to the speed at which the sample solution passes through the cartridge column. Thus, the timing is not adequate for the equilibrium to be established between the surface of the adsorbent and the analytes which eventually leads to a reduction in analyte recovery (Sharma and Pant 2009; Sabermahani et al. 2011). Thus, a flow rate of $2 \mathrm{~mL} / \mathrm{min}$ was selected for subsequent experimental test runs.

Influence of the type and concentration of eluents

The quantitative recovery of retained metal ions on PCAD polymeric materials, various concentration and volumes of nitric and hydrochloric acids were investigated. The influence of eluents type on the recovery of metal ions was also studied using nitric acid. The results given in Fig. 7 show that the quantitative recoveries $(80 \%)$ for the metal ions were obtained with $50 \mathrm{~mL}$ of $2 \mathrm{~mol} / \mathrm{L}$ of $\mathrm{HNO}_{3}$. Thus, in this study $20 \mathrm{~mL}$ of $2 \mathrm{M} \mathrm{HNO}_{3}$ was selected as eluents for the metal recovery.

The effect of different concentrations of nitric and hydrochloric acids on the preconcentration yields of the metal ions under the optimum $\mathrm{pH}$ condition was studied. The result shows that both acids can effectively elute the metal ions from PCAD polymeric materials in the cartridge (Fig. 7). However, $\mathrm{HNO}_{3}$ has higher recoveries than $\mathrm{HCl}$ and one would expect both acids to have the same recovery capacities as shown in Fig. 7. However, this is not the case, despite both acids having the same hydroxonium ion. $\mathrm{HNO}_{3}$ has an edge due to its oxidation capacity (Malla et al. 2002). It was also observed that $\mathrm{HCl}$ has a low recovery at $3.0 \mathrm{M}$ as shown in Fig. 7. This could be due to the formation of stable complexes in the presence of chloride ions which 

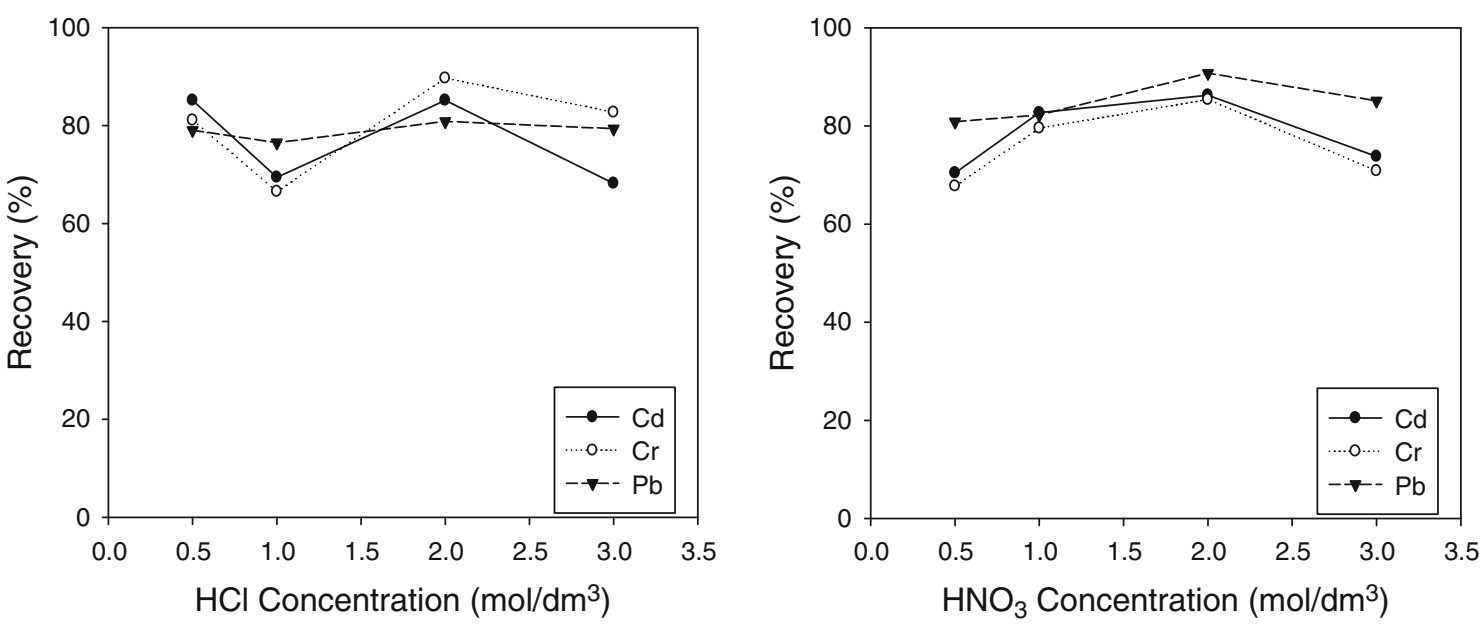

Fig. 7 Influence of type and concentration of eluents on the recoveries of metal ions in aqueous medium

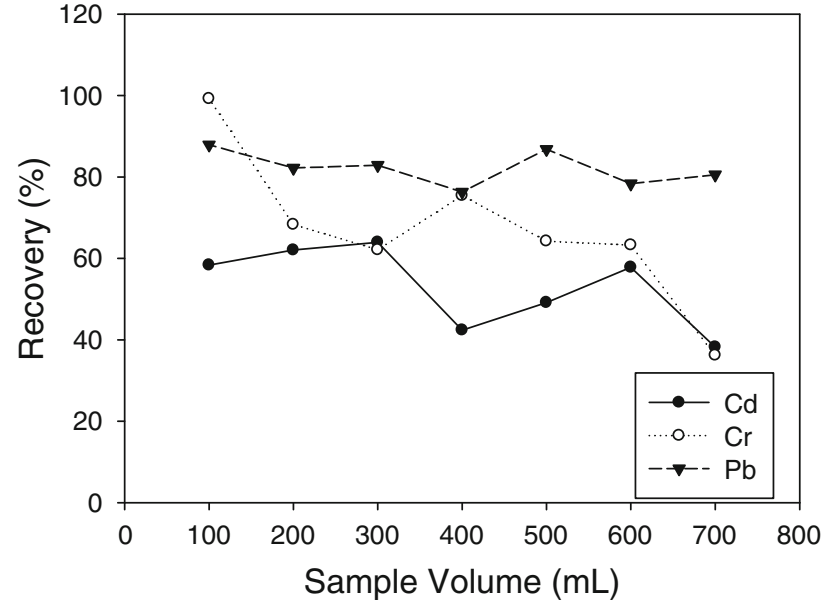

Fig. 8 Influence of sample volume on the recoveries of metal ions in aqueous medium

explain the low recovery experienced for $\mathrm{HCl}$ when used as eluents (Tuzen et al. 2005). Thus, $\mathrm{HNO}_{3}$ was selected as eluents for desorption of the metal ions from PCAD polymeric material.

Influence of sample volume

The influence of the sample volume on the recovery and preconcentration factor is one of the vital parameters for obtaining high exchange capacity (Ngah et al. 2012). In order to determine the maximum applicable sample volume for analyte concentration, there is a need to examine the possibility of enriching low concentrations of analytes from large sample volumes. To achieve this purpose, the concentrations of each metal ion were kept relatively constant with increasing sample volume. The influence of sample volume was studied by passing $100-500 \mathrm{~mL}$ of model sample solution through PCA polymeric materials packed cartridge under the optimum conditions (Fig. 8). The recoveries of the metal-ion analytes were greater than $70 \%$. The preconcentration factor was calculated by the ratio of highest volume to the lowest volume of eluents. Hence, $5 \mathrm{~mL}$ sample volume solution was adopted for the preconcentration factor.

Comparison of PCAD polymeric material with other methods of metal-ion extraction

The comparison of PCAD polymeric material with other methods of extraction was carried out to show the extraction efficiency and determination of metal ion in water sample. The comparison result (Fig. 9) showed that PCAD polymeric materials were applied as a stationary phase to preconcentrate and purify metal ions in aqueous solution. The average recoveries of PCB analytes for all PCA polymeric material including AC and C18 (59\% for MDI, $82 \%$ for MDIAC, $85 \%$ for MDICD, $92 \%$ for MDIACCD, $65 \%$ for MDIRT, $70 \%$ for AC and $76 \%$ for C18 cartridge) revealed that the PU composite material with the filler $\beta-C D$ and AC, i.e. MDIACCD (Fig. 9) enhances the extraction efficiency of PCBs more than the other extraction techniques.

\section{Method validation}

A series of standard solutions were prepared to obtain a linear range for each of the metal-ion analytes. Table 2 


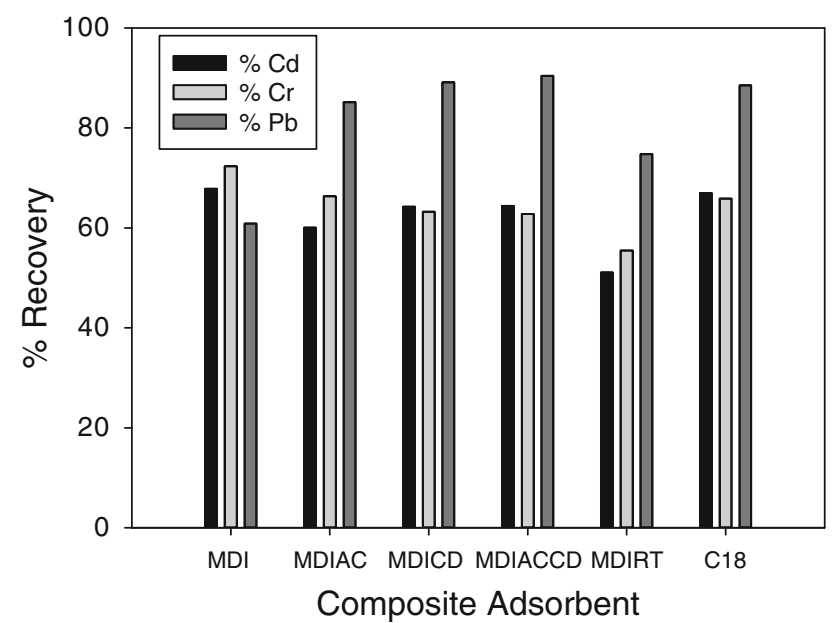

Fig. 9 Influence of composite adsorbents on the recoveries of metal ions in aqueous medium

Table 2 The limit of detection, limit of quantification and reproducibility method

\begin{tabular}{lllll}
\hline Analytes & $\begin{array}{l}\text { Calibration } \\
\text { equations }\end{array}$ & $\begin{array}{l}\text { Linear } \\
\text { correlation } \\
\text { coefficients }\left(r^{2}\right)\end{array}$ & $\begin{array}{l}\text { LOD } \\
(\mathrm{ng} / \\
\mathrm{mL})\end{array}$ & $\begin{array}{l}\text { LOQ } \\
(\mathrm{ng} / \\
\mathrm{mL})\end{array}$ \\
\hline $\mathrm{Cd}^{2+}$ & $Y=0.269 x+1.731$ & 0.936 & 0.256 & 0.855 \\
$\mathrm{Cr}^{3+}$ & $Y=0.186 x+11.15$ & 0.988 & 0.249 & 0.831 \\
$\mathrm{~Pb}^{2+}$ & $Y=0.276 x+1.555$ & 0.963 & 0.252 & 0.841 \\
\hline
\end{tabular}

shows the linearity range of the prepared standard solutions. The correlation coefficient $\left(r^{2}\right)$ of the PCB analytes ranges between 0.936 and 0.988 . The limit of detection LOD which is a signal-to-noise ratio (3:1) or response of standard deviation to the slope of analytical curve $\left(3.3 \times \frac{s}{b}\right)$ ranges from 0.249 to 0.256 . The limit of quantification (LOQs) based upon the signal-to-noise ratio (10:1) or standard deviation of the blank on the residual regression line $\left(10 \times \frac{s}{b}\right)$ ranges between 0.831 and 0.855 of the metalion analytes. A comparison of the method and adsorbent material is shown in Fig. 9. The obtained LOD and LOQ are comparable with some reported studies (Ensafi et al. 2003; Otero-Romani et al. 2005; Huang et al. 2008; Sharma and Pant 2009).

\section{Conclusion}

The present study demonstrates the preparation and use of an adsorbent based on polyurethane synthesis with different kinds of fillers. The modification of the polymeric composite material is simple and the composite material produced remained firm and could easily be packed into the SPE cartridges which invariably allowed it to be used several times. It could be concluded from the results that the PCAD produced is an effective adsorbent for preconcentration of metal ions from various sample solutions. The merit of the composite material includes high enrichment factor of (90), reproducibility, and low cost. The reusability of the adsorbent is high; about ten cycles without any loss in its adsorption capability.

Acknowledgments The authors would like to acknowledge the University of Johannesburg for funding (Grant No. 17011 URWC) this research project.

\section{References}

Absalan G, Mehrdjardi MA (2003) Separation and preconcentration of silver ion using 2-mercaptobenzothiazole immobilized on surfactant-coated alumina. Sep Purif Technol 33:95-101

Akl MAA, Kenawy IMM, Lasheen RR (2004) Organically modified silica gel and flame atomic absorption spectrometry: employment for separation and preconcentration of nine trace heavy metals for their determination in natural aqueous systems. Microchem J 78:143-156

Alkan M, Kalay B, Dogan M, Demirbas O (2008) Removal of copper ions from aqueous solutions by kaolinite and batch design. J Hazard Mater 153(1-2):867-876

Anthemidis AN, Themelis DG, Stratis JA (2001) Stopped-flow injection liquid-liquid extraction spectrophotometric determination of palladium in airborne particulate matter and automobile catalysts. Talanta 54:37-43

Anthemidis AN, Zachariadis GA, Stratis JA (2002) Online preconcentration and determination of copper, lead and chromium (VI) using unloaded polyurethane foam packed column by flame atomic absorption spectrometry in natural waters and biological samples. Talanta 58:831-840

Baraka A, Hall PJ, Heslop MJ (2007) Preparation and characterization of melamine formaldehyde-DTPA chelating resin and its use as an adsorbent for heavy metals removal from wastewater. React Funct Polym 67:585-600

Bulut Y, Tez Z (2007) Removal of heavy metals from aqueous solution by sawdust adsorption. J Environ Sci 19(2):160-166

Camel V (2003) Solid phase extraction of trace elements. Spectrochim Acta B At Spectrochim 58:1177-1233

Candir S, Narin I, Soylak M (2008) Ligandless cloud point extraction of $\mathrm{Cr}(\mathrm{III}), \mathrm{Pb}(\mathrm{II}), \mathrm{Cu}(\mathrm{II}), \mathrm{Ni}(\mathrm{II}), \mathrm{Bi}(\mathrm{III})$, and $\mathrm{Cd}(\mathrm{II})$ ions in environmental samples with tween 80 and flame atomic absorption spectrometric determination. Talanta 77:289-293

Castro RSD, Caetano L, Ferreira G, Padilha PM, Saeki MJ, Zara LF, Martines MAU, Castro GR (2011) Banana peel applied to the solid phase extraction of copper and lead from river water: preconcentration of metal ions with a fruit waste. Ind Eng Chem Res 50:3446-3451

Chen D, Hu B, Huang C (2009) Chitosan modified ordered mesoporous silica as micro-column packing materials for online flow injection-inductively coupled plasma optical emission spectrometry determination of trace heavy metals in environmental water samples. Talanta 78:491-497 
Duran A, Tuzen T, Soylak M (2009) Preconcentration of some trace elements via using multiwalled carbon nanotubes as solid phase extraction adsorbent. J Hazard Mater 169(1-3):466-471

Elci L, Kartal AA, Soylak M (2008) Solid phase extraction method for the determination of iron, lead and chromium by atomic absorption spectrometry using Amberlite XAD-2000 column in various water samples. J Hazard Mater 153(1-2):454-461

El-Sayed GO, Dessouki HA, Ibrahim SS (2010) Biosorption of Ni (II) and $\mathrm{Cd}$ (II) ions from aqueous solutions onto rice straw. Chem Sci J 9:1-11

Ensafi AA, Khayamian T, Karbasi MH (2003) Online preconcentration system for lead(II) determination in waste water by atomic absorption spectrometry using active carbon loaded with pyrogallol red. Anal Sci 19:953-956

Ferri T, Sangiorgio P (1996) Determination of selenium speciation in river waters by adsorption of iron(III)-chelex-100 resin and differential pulse cathodic stripping voltammetry. Anal Chimi Acta 321(2-3):185-193

Gayatri SL, Ahmaruzzaman M (2010) Adsorption technique for the removal of phenolic compounds from wastewater using low-cost natural adsorbents. Assam Univ J Sci Technol Phys Sci Technol $5(2): 156-166$

Gode F, Moral E (2008) Column study on the adsorption of $\mathrm{Cr}$ (III) and $\mathrm{Cr}(\mathrm{VI})$ using Pumice, Yarlkkaya brown coal, Chelex-100 and Lewatit MP 62. Biores Technol 99:1981-1991

Gupta VK, Nayak A (2012) Cadmium removal and recovery from aqueous solutions by novel adsorbents prepared from orange peel and $\mathrm{Fe}_{2} \mathrm{O}_{3}$ nanoparticles. Chem Eng J 180:81-90

Gupta VK, Singh P, Rahman N (2004) Adsorption behavior of $\mathrm{Hg}(\mathrm{II})$, $\mathrm{Pb}(\mathrm{II})$, and $\mathrm{Cd}(\mathrm{II})$ from aqueous solution on Duolite C-433: a synthetic resin. J Colloid Interface Sci 275(2):298-402

Gupta VK, Rastogi A, Nayak A (2010) Biosorption of nickel onto treated alga (Oedogonium hatei): application of isotherm and kinetic models. J Colloid Interface Sci 342:533-539

Gupta VK, Agarwal S, Saleh TA (2011a) Chromium removal by combining the magnetic properties of iron oxide with adsorption properties of carbon nanotubes. Water Res 45:2207-2212

Gupta VK, Agarwal S, Saleh TA (2011b) Synthesis and characterization of alumina-coated carbon nanotubes and their application for lead removal. J Hazard Mater 185:17-23

Gupta VK, Ganjali MR, Norouzi P, Khani H, Nayak A, Agarawa S (2011c) Electrochemical analysis of some toxic metals by ionselective electrodes. Critical Rev Anal Chem 41(4):282-313

Gupta VK, Ganjali MR, Nayak A, Bhushan B, Agarwal S (2012a) Enhanced heavy metals removal and recovery by mesoporous adsorbent prepared from waste rubber tire. Chem Eng J 197:330-342

Gupta VK, Ali I, Saleh TA, Nayak A, Agarwal S (2012b) Chemical treatment technologies for waste-water recycling-an overview RSC. Advances 2(16):6380-6388

Huang X, Chang X, He Q, Cui Y, Zhai Y, Jiang N (2008) Tris(2Aminoethyl) amine functionalized silica gel for solid-phase extraction and preconcentration of $\mathrm{Cr}(\mathrm{III}), \mathrm{Cd}(\mathrm{II})$ and $\mathrm{Pb}(\mathrm{II})$ from waters. J Hazard Mater 157:154

Jain AK, Gupta VK, Bhatnagar A, Suhas A (2003) A comparative study of adsorbents prepared from industrial wastes for removal of dyes. Sep Sci Technol 38(2):463-481

Kiliaris P, Papaspyrides CD (2010) Polymer/layered silicate (clay) nanocomposites: an overview of flame retardancy. Prog Polym Sci 35:902-958

Kocaoba T, Akyuz T (2005) Effects of conditioning of sepiolite prior to cobalt and nickel removal. Desalination 181(1-3):313-318

Krause RWM, Mamba BB, Bambo FM, Malefetse TJ (2010) Cyclodextrin polymers: synthesis and application in water treatment. In: Hu J (ed) Cyclodextrins: chemistry and physics, vol 9. Transworld Research Network, Kerala, pp 185-208

Li A, Zhang Q, Zhang G, Chen J, Fei Z, Liu F (2002) Adsorption of phenolic compounds from aqueous solutions by a watercompatible hypercrosslinked polymeric adsorbent. Chemosphere 47:981-989

Madrakian T, Zolfigol MA, Solgi M (2008) Solid-phase extraction method for preconcentration of trace amounts of some metal ions in environmental samples using silica gel modified by $2,4,6$ trimorpholino-1,3,5-triazin. J Hazard Mater 160:468-472

Malla ME, Alvarez MB, Batistoni DA (2002) Evaluation of sorption and desorption characteristics of cadmium, lead and zinc on Amberlite IRC-718 iminodiacetate chelating ion exchanger. Talanta 57:277-287

Mittal A, Mittal J, Malviya A, Gupta VK (2009) Adsorptive removal of hazardous anionic dye "Congo red" from wastewater using waste materials and recovery by desorption. J Colloid Interface Sci 340(1): 16-26

Mittal A, Mittal J, Malviya A, Gupta VK (2010) Removal and recovery of Chrysoidine $\mathrm{Y}$ from aqueous solutions by waste materials. J Colloid Interface Sci 344(2):497-507

Mohammadi SZ, Afzali D, Pourtalebi D (2011) Flame atomic absorption spectrometric determination of trace amounts of palladium, gold and nickel after cloud point extraction. J Anal Chem 66(7):620-625

Ngah WS, Teong LC, Toh RH, Hanafiah MAKM (2012) Utilization of chitosan-zeolite composite in the removal of $\mathrm{Cu}$ (II) from aqueous solution: adsorption, desorption and fixed bed column studies. Chem Eng J 209:46-53

Olorundare OF, Krause RWM, Okonkwo JO, Mamba BB (2012) Potential application of activated carbon from maize tassel for the removal of heavy metals in water. J Phys Chem Earth 50-52:104-110

Oprea S (2008) Effects of fillers on polyurethane resin-based polyurethane elastomeric bearing materials for passive isolation. J Compos Mater 42(25):2673-2685

Oprea S (2011) Preparation and characterization of the agar/polyurethane composites. J Compos Mater 45(20):2039-2045

Otero-Romani J, Moreda-Pineiro A, Bermejo-Barrera A, BermejoBarrera P (2005) Evaluation of commercial C18 cartridges for trace elements solid phase extraction from seawater followed by inductively coupled plasma optical emission spectrometry determination. Anal Chim Acta 536:213-218

Pan L, Qin YR, Hu B, Jiang ZC (2007) Determination of nickel and palladium in environmental samples by low temperature ETVICP-OES coupled with liquid- liquid extraction with dimethylglyoxime as both extractant and chemical modifier. Chem Res Chin Univ 23(4):399-403

Pinto ML, Pires J, Carvalho AP, Carvalho MB, Bordado JC (2004) Synthesis and characterization of polyurethane foam matrices for the support of granular adsorbent materials. J Appl Polym Sci 92:2045

Pinto ML, Pires J, Carvalho AP, Carvalho MB, Bordado JC (2005) Characterization of adsorbent materials supported on polyurethane foams by nitrogen and toluene adsorption. Microporous Mesoporous Mater 80:253-262

Rafati L, Mahvi AH, Asgari AR, Hosseini SS (2010) Removal of chromium(VI) from aqueous solutions using Lewatit FO36 nano ion exchange resin. Int $\mathbf{J}$ Environ Sci Technol 7(1): $147-156$

Rezaei B, Sadeghi E, Meghdadi S (2009) Nano-level determination of copper with atomic absorption spectrometry after pre-concentration on N, N-(4-methyl-1, 2-phenylene) diquinoline-2-carboxamide-naphthalene. J Hazard Mater 168(2):787-792 
Sabermahani F, Taher MA, Bahrami H, Fozooni S (2011) Alumina coated with oxazolone derivative for extraction of trace amounts of cadmium and copper from water and plant samples. J Hazard Mater 185(2-3):945-950

Sanghavi BJ, Mobin SM, Mathur P, Lahiri GK, Srivastava AK (2013) Biomimetic sensor for certain catecholamines employing copper(II) complex and silver nanoparticle modified glassy carbon paste electrode. Biosens Bioelectron 39:124-132

Sharma RK, Pant P (2009) Pre-concentration and determination of trace metal ions from aqueous samples by newly developed gallic acid modified Amberlite XAD-16 chelating resin. J Hazard Mater 163:295-301
Soylak M, Tuzen M (2008) Coprecipitation of gold(III), palladium(II) and lead(II) for their flame atomic absorption spectrometric determinations. J Hazard Mater 152(2):656-661

Tuzen M, Parlar K, Soylak M (2005) Enrichment/separation of cadmium(II) and lead(II) in environmental samples by solid phase extraction. J Hazard Mater 121:79-87

Zhang L, Chang X, Hu Z, Zhang L, Shi J, Gao R (2010) Selective solid phase extraction and pre-concentration of mercury(II) from environmental and biological samples using nanometer silica functionalized by 2,6-pyridine dicarboxylic acid. Microchim Acta 168:79-85 